\title{
Habitar un rol: la tarea del profesor adscriptor de Comunicación visual-Dibujo como oportunidad para reflexionar sobre sus prácticas*
}

María Borges**

"(...) un espacio es habitable sólo si pasan dos cosas: el que lo habita se altera por habitarlo y el espacio se altera por ser habitado, o sea, si permite deformaciones de los dos lados".

Lewkowicz, 2004

\begin{abstract}
The adjunct teacher takes part in the training of the teacher learners of Visual Communication Arts at the Artigas Teachers' Institute, together with the Didactics teacher. The presence of the teacher learner enables the reflection process as well as the analysis of the mentor's teaching practice.
\end{abstract}

This research had a qualitative approach which allowed us to account for the characteristics of the mentor's teaching practices as well as the elements which account for the reflection and analysis on these practices.

Within the framework of teacher's training, visual communication and the teaching practice can be considered as subjectivizing open spaces, allowing individual approaches to the role and task. The processes of reflection and analysis of the practices are made evident trhough the search of heuristic teaching practices, with an epistemological and ethical sense. Heuristics implies the chance of error and the uncertainty of what has been found.

\section{Resumen}

El profesor adscriptor participa de la formación de estudiantes de profesorado de Comunicación visual del Instituto de Profesores Artigas, junto con el profesor de Didáctica. La presencia del estudiante practicante habilita procesos de reflexión y análisis de las prácticas de enseñanza del profesor adscriptor.

La investigación tuvo un enfoque cualitativo que permitió aproximarnos a las características de las prácticas de enseñanza de profesores adscriptores y a elementos que dan cuenta de la reflexión y análisis de esas prácticas.

La Comunicación visual y la práctica docente en el marco de la formación docente son concebidas como espacios subjetivantes abiertos que permiten modos singulares de habitar el rol y la tarea. Los procesos de reflexión y análisis de las prácticas se evidencian a través de la búsqueda de prácticas heurísticas de enseñanza, con sentido epistemológico y ético. Lo heurístico entraña la posibilidad de equivocación y la no certeza de lo encontrado. 


\section{Descubriendo el territorio...}

\section{... del tema...}

La formación docente en el marco del Instituto de Profesores Artigas (IPA) se organiza en un Plan de estudios de cuatro años en torno a asignaturas de un tronco común (Ciencias de la Educación) y asignaturas específicas de la disciplina; dentro de éstas se encuentra la Unidad Didáctica - Práctica docente. La práctica docente supone una tríada de actores: un estudiante, un profesor de Didáctica y un profesor adscriptor.

Un profesor experimentado es profesor adscriptor en tanto haya un estudiante de profesorado que lo invista de ese carácter; deviene adscriptor en relación con el practicante. Esto supone para nosotros, construir -se en el rol desde la tarea con el estudiante practicante, de un modo particular, en un espacio - tiempo determinado. La dimensión espacio - temporal nos lleva a pensar en un estar - siendo profesor adscriptor en - situación que se vive, que se habita de un modo único desde lo profesional y que nos remite a la subjetividad que atraviesa todas las prácticas humanas, incluyendo las prácticas del pensar. Es en este sentido que consideramos la reflexión como una práctica más del profesor adscriptor. Cuando decimos "más" no nos referimos a una cuestión sumativa, que se agrega a su tarea, sino a una práctica que suponemos inherente a la misma.

El profesor adscriptor carece de formación específica para desempeñarse como docente en el acompañamiento del proceso de aprendizaje de las prácticas de enseñanza de un docente en formación. Visto este vacío, en el período 2005-2007 se desarrollaron cursos de carácter semipresencial para quienes ya lo fueran o aspiraran a serlo, en el marco del Instituto de Perfeccionamiento y Estudios Superiores (en adelante IPES) de la Administración Nacional de la Enseñanza Pública (en adelante ANEP).

El docente que asume dicho caracter, desarrolla una tarea que supone un alto grado de complejidad: enseñar Comunicación visual ${ }^{1}$ a los estudiantes del curso que tiene a cargo en una institución de educación media y simultáneamente, acompañar a un estudiante de profesorado del Instituto de Profesores Artigas (en adelante IPA) en su aprendizaje del rol y tarea de enseñar. Este acompañamiento implica analizar las prácticas (de aula y las que trascienden la misma) con el estudiante practicante. Nos preguntamos entonces, ¿ de qué manera la tarea del profesor adscriptor de Comunicación visual - Dibujo le permite la reflexión a partir del análisis de sus propias prácticas?

Nos propusimos indagar elementos de reflexión en torno a las prácticas de enseñanza de los profesores adscriptores de Comunicación visual - Dibujo (en adelante CV-D) para comprender la manera en que se produce la reflexión en ellos, desde la visión de los actores involucrados. Asimismo, nos planteamos detectar prácticas de enseñanza de profesores adscriptores de CV D en presencia de estudiantes de profesorado para comprender las características que asumen dichas prácticas en el espacio de la práctica docente correspondiente al curso de Didáctica del IPA. Buscamos también aproximarnos a elementos teóricos referidos a la reflexión en torno al análisis de las prácticas de los profesores adscriptores de CV - D, lo que permitiría la comprensión de aspectos de un tema poco investigado en nuestro país, que aspiramos aporte elementos al conocimiento de dichas prácticas. 


\section{Subjetividad e implicancias}

Al proponernos investigar estos aspectos relativos al profesor adscriptor, nos fue necesario incluirnos desde nuestra propia subjetividad (retomaremos este aspecto). Incluirnos adquiere el sentido de escribir acerca del modo propio de estar habitando nuestro rol de profesora adscriptora, desde el momento del reconocimiento del deseo de serlo. Habitar como una forma de vivir en la realidad, de residir en ella con un modo propio, de manera que a su vez nos va diseñando y construyendo en nuestros espacios interiores; habitar como construcción continua que deviene en un interjuego de acciones en espacios - tiempos que se presentifican.

En primer lugar, reconocimos que nuestra experiencia docente en un centro de educación media pública que recibía por año un promedio de cuarenta estudiantes de profesorado de distintas disciplinas, unida a nuestra condición de profesora adscriptora inicial, nos ha llevado a pensar en diversos aspectos relativos a los actores involucrados en las instancias de práctica docente en la formación inicial de profesorado. También tuvimos que re-conocernos desde nuestra historia de formación o mejor aún desde sus trazas ${ }^{2}$, re-significándolas. Incluir nuestra subjetividad entonces, fue re-conocer(nos) en nuestras representaciones, creencias y presupuestos y "suspenderlos" (Taylor y Bogdan, 2000).

\section{Fundamentación}

La bibliografía consultada con respecto a formación docente (Días, 2006; Vaillant, 2002; Díaz, 2004; Davini, 1995; Edelstein y Coria, 1995; Imbernón, 1994) considera la importancia que adquiere la figura formadora con relación a los docentes en formación y docentes iniciales, pero no se plantea como tema de estudio los efectos que la presencia del estudiante puede generar en el análisis y la reflexión sobre las prácticas de su tutor.

Otro elemento a tener en cuenta es que el estudiante - practicante es un observador de la práctica de un docente experimentado, de modo tal que éste es un formador observado. A su vez el profesor adscriptor observará la práctica del estudiante, en ocasiones en conjunto con el profesor de Didáctica. Esta tríada de actores complejiza los fenómenos que se suceden en el aula. Atención particular merecería el caso en que el profesor de Didáctica sea inspector de la asignatura.

Compete al profesor adscriptor analizar su práctica con el estudiante a fin de que éste comprenda la situación singular de enseñanza, entendiéndola desde la articulación teoría - práctica que sabemos plantea zonas conflictivas. Un riesgo podría darse al producirse desfasajes entre los conocimientos y prácticas del profesor adscriptor y los contenidos desarrollados en el IPA. Por otra parte, el profesor adscriptor representa a la institución, contexto en el cual se inscriben sus prácticas de enseñanza que son parte de las prácticas docentes que trascienden el universo particular del aula: su participación en el proyecto de centro, su vínculo con otros actores del centro, su compromiso, aspectos estos que hacen al oficio de enseñar y que vemos conveniente integrar a la formación docente.

Por lo planteado anteriormente, consideramos importante dirigir nuestra mirada a las prácticas de enseñanza del profesor adscriptor de las que se deriven elementos de análisis de las mismas y suponemos instancias de reflexión en presencia del estudiante practicante, así como la visión que tienen aquellos de sus propios procesos reflexivos. Nos planteamos en definitiva, una mirada al modo en que los profesores adscriptores habitan su rol desde la tarea. Afirmamos con Heidegger (1994:119) que "(...) Se habría ganado bastante si habitar y construir entraran en lo que es digno de ser preguntado y de este modo quedaran como algo que es digno de ser pensado." Habitar que implica cuidar en el sentido de "mirar por". Preguntar(se) y pensar(se)... parpadeos necesarios en la mirada desde y sobre las prácticas. 


\section{La forma que se va adoptando en el tiempo}

Formación, de acuerdo al Diccionario de la Real Academia Española (2001) es "dar forma a una cosa", "adquirir una persona más o menos desarrollo físico, intelectual o moral", en tanto que forma es la configuración externa de algo, el modo de proceder en algo o el molde en que se vacía y forma algo.

Souto (1999) concibe la formación como proceso inacabado que se vincula a la existencia individual y social. Para Beillerot (1998:30) la formación es el“(...) aprendizaje del savoir faire (saber hacer), y también una adquisición de técnicas, así como una adquisición de juicio y de marcos de pensamiento" y afirma que tiene que ver con las capacidades conscientes de la persona, con su afectividad, su imaginario y su inconsciente en la historia del sujeto, a la vez que lo historiza. Imbernón (1994:11) entiende la formación unida al desarrollo profesional, “(...) ver la formación como un aprendizaje constante, acercando ésta al desarrollo de actividades profesionales y a la práctica profesional y desde ella", concibiéndola como un continuo progresivo que permite pensar la práctica de la enseñanza como profesión dinámica que se desarrolla en contextos específicos.

Pese a esta consideración, Imbernón (1994) reconoce por lo menos tres etapas: una inicial, otra de formación básica, y por último, una de socialización profesional que se caracteriza por la formación inicial en instituciones específicas. En esta última a su vez, hay un tiempo de inducción profesional y socialización en la práctica que corresponde a los primeros años de ejercicio y otro de perfeccionamiento que se caracteriza por la formación permanente. Por su parte, Davini (1995) plantea tres fases en la formación docente: la biografía escolar previa, la formación de grado y la socialización laboral en la práctica escolar. Pensándolo así, el tiempo de formación docente es un espacio - tiempo entre, entendido como transicional, frontera entre el estudiante que fue y aún es y el profesional que será.

Pensamos la formación como la forma que uno va adoptando en el tiempo tratando de desarrollar lo que se es. De modo general, concebimos la práctica como espacio de formación, de investigación, de construcción de conocimiento y de re - conocimiento de los esquemas de pensamiento y acción propios, para poder operar sobre ellos, a través del análisis reflexivo; de construcción de autorías desde la autonomía que no es la soledad, desde una mirada compleja que trascienda el aula y considere la institución educativa, la comunidad en que se encuentra y el contexto socio - histórico.

\section{Los escenarios de la Formación y práctica docentes}

\section{El Instituto de Profesores Artigas y los centros de Educación Secundaria}

Los antecedentes de la formación de docentes para actuar en Enseñanza Secundaria se ubican en la Sección de Agregaturas de Enseñanza Secundaria (1936 -1945). El IPA comienza a funcionar en 1951 con un Plan de estudios de cuatro años organizado con un tronco común de asignaturas cuya composición alude a las comúnmente denominadas Ciencias de la Educación (el cincuenta por ciento del currículo) y las asignaturas específicas que aluden a la formación disciplinar correspondiente a cada especialidad; dentro de éstas se ubica la práctica docente como parte de los cursos de Didáctica. De esta forma se contemplan tres aspectos fundamentales de la formación docente: la aptitud y el conocimiento de la disciplina que enseñará; la formación pedagógica, y la formación práctica en centros de la enseñanza media (Grompone, 1952). La situación de dependencia del Consejo de Enseñanza Secundaria (en adelante CES) le permitió mantener la relación con los liceos y organizar la práctica docente del alumnado. 
En los cursos de Didáctica I y II, correspondientes al segundo y tercer año de formación, el estudiante realiza la práctica docente concurriendo durante todo el año lectivo a las clases de un grupo de un profesor adscriptor que él elige de una lista elaborada por la Inspección correspondiente, en cualquier centro educativo y turnos; ésta incluye visitas periódicas del profesor de Didáctica que lo orienta. En el caso de Didáctica I de CV-D la práctica se realiza en un liceo de Ciclo Básico y la de Didáctica II en uno de Bachillerato. En cuarto año, Didáctica III, el estudiante tiene a cargo un grupo, con todos los derechos y obligaciones estipulados en el Estatuto del Funcionario Docente.

Nos interesa señalar la posibilidad que tienen los estudiantes de profesorado del IPA de realizar la práctica docente en cualquier centro educativo de enseñanza media. Grompone (1956) sostenía que no era conveniente la creación de un centro modelo para la práctica docente, fundamentando que era beneficioso que el estudiante conociera las dificultades que se presentan en la realidad de actuación profesional. Subrayamos esta intención dado que es esperable que el IPA forme docentes capaces de adaptarse al medio educacional y social en que van a trabajar, suponiendo adaptación en forma activa y crítica, tomando la noción de desadaptación creativa (Fernández, 2000:105). Destacamos este aspecto teniendo en cuenta que los docentes iniciales, generalmente, concentran sus horas de trabajo en liceos de Ciclo Básico, altamente complejos por las características de la población estudiantil que atienden.

...de los guiones teóricos...

...de las prácticas de formación

En la pesquisa bibliográfica (Atkinson, 2002; Beillerot, 1998; Ropo, 1998; Schön, 1998) hemos encontrado variaciones en las características de las prácticas de formación inicial, que dependen de los diseños curriculares de las instituciones formadoras pero asumen un rasgo común que es la participación de por lo menos dos actores en un vínculo que puede adoptar denominaciones y organizaciones diversas pero que involucra a ambos en el análisis de las prácticas de la disciplina, problematizando la articulación de teoría y práctica.

Estableceremos una diferenciación entre profesional experto y profesional experimentado. Consideraremos a éste como un práctico eficaz (Ropo, 1998). Centraremos el concepto en el saber - hacer del docente en contextos específicos, aspecto que lo diferenciaría del experto. De acuerdo a Ropo, pueden establecerse cuatro categorías referidas a la pericia, a saber: una, relacionada con las habilidades técnicas que se pueden identificar en un individuo en situaciones prácticas, plausibles de ser transmitidas. Una segunda categoría considera la pericia como aplicación de la teoría. La tercera está relacionada al análisis crítico de las situaciones a nivel de los paradigmas. La última perspectiva la vincula con las acciones deliberadas y el análisis de situaciones en el contexto de acción. El profesional experimentado se distinguiría del experto en cuanto al "grado de experiencia" considerado como uno de los criterios que definen la pericia.

La pericia del profesional experimentado se corresponde con la categoría que alude a las habilidades técnicas puestas en juego en situaciones prácticas y con la de análisis de procedimientos, pero no alcanza el grado de análisis de paradigmas del campo disciplinar. Bransford y Vye (1996) afirman que los docentes expertos son capaces de controlar y administrar su aprendizaje, lo que deriva en procesos metacognitivos. Beillerot (1998) considera que el experto es reconocido por su experiencia y su saber con relación al oficio; el saber refiere al discernimiento y está centrado en la experiencia y la sapiencia. En este sentido, el docente experimentado se centraría en la experiencia sin alcanzar el grado de discernimiento, entendido éste como primera acepción de la palabra ciencia, quedando excluido por ejemplo el análisis epistemológico. El profesional experimentado, ha adquirido pericia porque ha logrado "(...) el manejo, espontáneo y 
fluido, de campos de acción familiares pero complejos" (Claxton, 2002: 53), tratándose de un saber - práctico. Éste nos remite al sentido práctico propuesto por Bourdieu (1991), que es comprensión práctica y se adecua a la lógica de la situación permitiéndole al sujeto enfrentar rápidamente situaciones ambiguas o de incertidumbre del campo en el que actúa (Edelstein, 1995).

El sentido práctico es la lógica con la que opera el habitus. Éste es“(...) es historia incorporada, naturalizada, (...) presencia activa de todo el pasado del que es producto" (Bourdieu, 1991: 98) en forma de esquemas de percepción, de pensamiento y acción. Son "sistemas de disposiciones duraderas y transferibles" que se estructuran a partir de la socialización primaria del sujeto y es estructurante de prácticas y representaciones acerca de esas prácticas. Dispone al sujeto a generar (desde el pasado) estrategias que le permiten afrontar situaciones diversas en la urgencia (del presente) y escapan a la conciencia; si bien deriva de aquí la noción de sujeto - sujetado, las disposiciones pueden variar cuando el sujeto se enfrenta a situaciones diferentes a aquellas que generaron el habitus.

De lo desarrollado anteriormente y desde otra línea teórica, deriva la importancia de la intuición en el desarrollo de la pericia profesional. En lenguaje popular, el "ojo clínico" da cuenta de la intuición. Pero más allá de la metáfora, tanto la intuición como la visión constituyen formas no racionales de conocimiento, basadas en la percepción de informaciones mínimas y orientan la toma de decisiones operando como patrones (Eisner, 1998). Los profesionales experimentados extraen significados a partir de informaciones mínimas basándose en una amplia base de datos derivados de la experiencia. El conocimiento teórico, racional y racionalizado, en algunas situaciones obstaculizaría una mirada nueva o distinta de la situación.

Claxton (2002) sostiene que la idea de intuición remite a distintas "formas de saber" de la práctica: a la pericia, al aprendizaje implícito, al juicio, a la sensibilidad, a la creatividad y resolución de problemas, a la cavilación. Se relaciona con la capacidad de utilizar sus experiencias de un modo nuevo, flexible e integrador, características que remiten al pensamiento divergente (Arieti, 1993) y deriva en la idea de creatividad. Ésta, en su acepción vulgar, alude a las soluciones originales y novedosas que un individuo puede dar a situaciones cotidianas. Refiere también a descubrimientos o acciones que cobran importancia para un individuo. Ambas acepciones reducen la creatividad a un fenómeno subjetivo. Csikszentmihalyi (1998) plantea la creatividad como un sistema de interacciones entre un sujeto, un campo y un ámbito de modo tal que el sujeto, utilizando los símbolos de un dominio o campo dado, concibe algo con carácter de novedad y su obra o producción es seleccionada por el ámbito de expertos correspondiente para ser incluida en el campo. En el caso de la formación docente, el experto puede hacer aportes o generar innovaciones en el campo profesional pero nos preguntamos de qué manera se validan las prácticas creativas del profesor adscriptor.

\section{...de los actores...}

El relevamiento bibliográfico nos dio elementos para comprender los procesos de socialización en una cultura profesional de los profesores principiantes, considerando esta etapa como la que transcurre durante los tres primeros años de actividad (Días, 2006; Biddle, Good et.al, 2000; Edelstein, 1995; Resnick, 1996; Imbernón, 1994). Bullough (2000) diferencia el proceso de formación del profesorado con respecto a otros campos, dado que como estudiantes conocen qué es la enseñanza por haber sido y ser alumnos, y, en ocasiones, por su práctica de enseñanza previa a la formación en una institución docente. Esto que podría ser una ventaja, se transforma a veces en un obstáculo por el peso de las concepciones de aprendizaje y de enseñanza. 
Pensamos las concepciones de aprendizaje y de enseñanza como modos de entender las nociones de aprender, enseñar, conocimiento, poder e identidad y se ponen de manifiesto en las acciones y en lo discursivo; están atravesadas por el sentido común y por la historia personal y para el sujeto darán cuenta de la realidad misma. Una de estas concepciones, tanto de los practicantes como de los docentes novatos, es considerar la experiencia práctica en el aula como el elemento más importante de la formación; de esta manera se da una desarticulación entre la formación pedagógica y la didáctica (Boullogh, 2000; Edelstein, 1995). Esta fragmentación entorpece la comprensión y análisis de la complejidad de las situaciones de aula; una forma de defensa es la proyección de desconcierto y/o angustia en los alumnos o de la negación en la acción de lo sostenido a nivel discursivo. Por otra parte, presentan dificultades de articular el conocimiento teórico y la práctica, actuando muchas veces por imitación, ensayando estrategias observadas en profesores experimentados que los ayuden a llevar adelante una práctica más eficaz frente a situaciones problemáticas (Imbernón, 1994; Atkinson, 2002). En el caso de los docentes novatos en nuestro país aparecen como referentes los profesores adscriptores y los profesores de Didáctica (Días, 2006). Hay tensiones que se despliegan en ambos. En el docente novato, la del ser reconocido como profesor por sus alumnos y colegas; en el estudiante de profesorado, la búsqueda de "ser uno mismo" en tensión con lo que es requerido formalmente en una práctica que será evaluada por su profesor.

Con respecto a la relación entre estudiante de profesorado y profesor formador encontramos diferentes denominaciones: mentorazgo, tutoría, asesoría, orientación y monitoreo (Díaz, 2004; Lazarus, 2002; Edelstein y Coria, 1995). Todas son acciones que suponen la orientación de un experimentado a un sujeto en formación, adquiriendo más o menos direccionalidad. Algunas características personales que los experimentados deberían reunir son: habilidad comunicativa, paciencia, flexibilidad, sensibilidad, ser capaces de crear vínculos de confianza, y otros de carácter profesional: experticia en la labor docente, comunicación con los compañeros y capacidad para planificar y organizar. Lazarus (2002:142) señala una serie de tareas que desempeñan los tutores: escuchar a los estudiantes, analizar y discutir su praxis, observar a los estudiantes y apoyarlos en su función docente promoviendo la autoevaluación aportándole elementos críticos, sin dejar de lado la intuición. Edelstein y Coria (1995) señalan que hay que "recuperar la idea de tutoría" desde una perspectiva constructivista, generar andamiajes en un contexto de conocimiento y comprensión compartido, de manera que el apoyo brindado sea provisorio hasta desaparecer progresivamente, asignando importancia al desarrollo de la metacognición. Señalan como necesarios la observación y el registro que permitirán identificar situaciones en que sería necesaria la intervención y en qué sentido, sin interferir en el proceso del practicante. El novato adquiere mayor compromiso y responsabilidad con relación a la tarea y finalmente asume la resolución de los problemas sin requerir de la intervención del tutor, lo que hablaría de la interiorización de los formatos y el andamiaje. La tutoría exige formación y colaboración por parte de distintos actores.

\section{...en el escenario local}

\section{El profesor adscriptor}

Para acceder al cargo de profesor adscriptor son condiciones necesarias integrar el escalafón de docentes efectivos en tercer grado, con un puntaje superior a 85/100. La Inspección de asignatura elabora la lista de profesores habilitados, considerando también aptitudes para el desempeño del rol, lo que alude a aspectos vinculares y a la disposición de compartir su conocimiento con otros. No se realiza una comunicación oficial a los docentes que integran la lista. Los profesores pueden aceptar o no a los practicantes. 
Una vez iniciados los cursos de Didáctica - Práctica docente, el equipo de profesores de Didáctica del IPA efectúa una sala inicial con los profesores adscriptores a fin de generar acuerdos para la tutoría conjunta de los practicantes. Se realiza también un relevamiento de posibles temas a trabajar e inquietudes en general. Se trabajan los perfiles de egreso del practicante correspondiente a cada nivel.

¿Con qué recursos cuenta el profesor adscriptor para esta práctica? Con su biografía personal y escolar, con sus modelos, con los conocimientos disciplinares, didáctico - pedagógicos, su experiencia, la formación brindada durante 2005-2007. Pero ¿son recursos suficientes? ¿Qué estrategias implementa en la construcción del rol?

Abrimos un paréntesis para considerar la palabra rol en sus diversas acepciones: "papel o función que alguien desempeña... personaje de la obra dramática representado por el actor" (DRAE, 2001); también como lista, enumeración, rollo. En este último sentido, lo relacionamos con las tareas que se asignan al profesor adscriptor y que fueron referidas anteriormente. Rol como rollo refiere a la materia que adquiere forma cilíndrica por rodar o dar vuelta, lo que nos lleva a pensar en la adquisición de una nueva forma por el movimiento, concepto que lleva implícito los de espacio y tiempo. Rollo también alude a las diversas láminas de papiro que enrolladas constituían un libro y que había que des-enrollar para ser leído. Esto nos lleva al significado de rol como el papel que desempeña un actor y el personaje de una obra dramática representado por aquel. Esta última acepción nos remite a la dramática que se juega desde el actor, en un doble movimiento que va del espacio interior al exterior y del exterior al interior, generando escenarios internos y externos en relación con otros, atravesados por el Otro.

Desde el momento en que un docente acepta "tener practicantes" y abre su aula a un otro en formación, asume el desafío de ser observado y observar, de mostrar y mostrarse en sus prácticas y vínculos, de hacerse tiempo para un otro desconocido en un espacio que le era propio. Nos preguntamos ¿Desde qué representaciones del docente adscriptor y del practicante se llevarán a cabo las prácticas de ambos? Porque "Su identidad se construye en la tensión entre lo que él quisiera ser, lo que otros creen que es y lo que él cree ser. Se construye anteponiendo y negando imágenes (Edelstein, 1995: 54)". Imágenes sobre sí mismo y sobre sus prácticas profesionales.

¿Cuáles son las prácticas de enseñanza que el profesor adscriptor desarrolla ante y con su practicante? ¿Qué recortes realiza en el diseño de una práctica que llevará a cabo en presencia de un practicante que observa? ¿En qué basa las opciones? En caso de tener más de un practicante, nuevamente ¿en qué basa sus opciones? También nos preguntamos por los aspectos transferenciales. ¿Difieren sus prácticas de enseñanza en presencia de un practicante - observador de aquellas en las que no oficia de profesor adscriptor? ¿Qué dimensiones de su propia práctica analiza con el practicante una vez terminada la clase? ¿Planifica sus clases con el practicante? En momentos en que es él quien se posiciona como observador de la práctica del estudiante ¿qué observa? ¿De qué manera realiza la devolución de la clase? ¿Propicia espacios para hacer inteligible la acción y lo implícito en ella? ¿Es capaz de descentrarse de su conocimiento, de su saber práctico, de sus creencias, para centrar su mirada en el practicante? ¿Qué lugar le otorga a la escucha del estudiante y a su práctica? ¿Es capaz de habilitar procesos de pensamiento y práctica autónomos?

Desde el momento en que el practicante se transforma en observador de la práctica del profesor adscriptor, el aula deja de ser una instancia privada de la mirada de otros actores de la institución. El practicante pertenece a otra institución y puede ser significado, como "representante' de la otra institución (Edelstein, 1995:52)" a la que el profesor adscriptor no pertenece y en la que su práctica se hará pública al ser comunicada en las clases de Didáctica a través de lo observado 
por el practicante. ¿De qué manera opera la presencia -ausente del docente de Didáctica? ¿puede éste constituirse en un observador y evaluador indirecto de las prácticas de enseñanza del profesor adscriptor?

\section{El practicante}

Realizar la práctica docente es iniciarse en la docencia. En un primer momento observa la práctica del profesor adscriptor y, avanzado el curso, hace sus propuestas de clase o desarrolla pequeños proyectos. Es visitado por su profesor de Didáctica, se realiza una devolución en conjunto al estudiante y luego se analiza la clase en el curso de Didáctica del IPA. La evaluación final del curso de Didáctica I consiste en una entrevista con un tribunal conformado por dos profesores de Didáctica y su profesor adscriptor, en tanto en Didáctica II la instancia final es una clase en presencia de un tribunal.

Si retomamos la noción de transicionalidad con respecto al espacio - tiempo entre de la formación docente, se plantea una frontera entre el estudiante que fue y aún es y el profesional que será; un tiempo de conocimiento pero también de re-conocimiento de los esquemas de pensamiento y acción propios para poder operar sobre ellos. Consideramos necesario plantear las tensiones que el doble rol genera en el estudiante de profesorado: ser estudiante y estar construyéndose docente, lo cual parece borrar las fronteras entre la formación de grado y la iniciación en la docencia. Por otra parte, operan en el practicante sus experiencias de aprendizaje que generan representaciones que dan cuenta de la realidad misma y que pondrá en juego en el encuentro con la práctica; sus representaciones serán cuestionadas si las acciones se basan en el pensamiento analítico y consciente.

Por las exigencias curriculares más que por "sentirse preparados", deben asumir la práctica de enseñanza, lo que lleva a un cambio de posicionamiento: de observador a actor, de estar en el lugar del que aprende a ser el que aprende a enseñar a otros. En ese momento son múltiples los elementos que atraviesan el aula: ansiedades, temores, demandas, las expectativas del practicante, del adscriptor, del profesor de Didáctica, de los alumnos. Es la puesta en escena del "como si fuera docente". Pensamos en el "como si" planteado por Winnicott (1972) como el espacio de juego, de creación.

Edelstein señala que se recuerdan las prácticas de formación como algo inédito, que no se vuelve a vivir y acordamos en parte con esta afirmación porque hay textos que a veces se repiten en otros contextos con significaciones diferentes, ya que el lugar desde el que se los experimenta es otro.

\section{...de la obra y la reflexión}

En las últimas décadas, la reflexión entendida como mirada crítica, fue adquiriendo importancia en el campo educativo, tanto en lo pedagógico como en lo didáctico, transformándose en elemento de la nueva agenda didáctica. Entendemos la reflexión como un "(...) proceso cognitivo o de pensamiento que se refleja en parte en el lenguaje (Furlong, en: Atkinson, 2002:37)”.

Schön (1998) plantea que la mayor parte de las conductas que un profesional despliega en sus prácticas, no son conscientes ni provienen del pensamiento explícito. “...la acción experta a menudo revela un 'saber más de lo que podemos decir' (1998: 57)” proponiendo que el conocimiento se da desde la acción, siendo el conocimiento práctico común el que alude a aquello de lo que a veces no podemos dar cuenta, ni somos conscientes de haberlo aprendido. Si durante la acción se presentan problemas o algo de la misma resulta sorprendente, la actividad no se detiene pero se toma conciencia de algunos aspectos puestos en juego en la misma, y del saber intuitivo 
implícito en la acción. En la medida en que se experimenta, la práctica se hace estable, en el sentido de lograr un repertorio adecuado de expectativas, imágenes y técnicas; el saber desde la práctica se hace más espontáneo y automático. Haber logrado una práctica especializada le permite a través de la reflexión posterior, explicitar y criticar lo implícito en la misma, resignificando situaciones de incertidumbre. La reflexión podrá generar entonces una nueva comprensión del problema o un cambio en la situación. Reflexionar desde la acción lleva al profesional a convertirse en investigador en un contexto práctico. Construye la teoría a partir de la complejidad de una situación única y peculiar que transforma en problema práctico, independientemente de teorías, técnicas o categorías establecidas. Esta reflexión desde la acción a veces adopta la forma de conversación reflexiva con la situación ya que implica mantener la multiplicidad de perspectivas de la situación. Consideramos que de este modo ya no sólo se trata de un pensamiento divergente sino de una práctica divergente.

A partir de la propuesta de Schön se da importancia a la reflexión sobre la práctica, esto es a posteriori de acontecida, en tanto favorecería el mejoramiento de las clases siguientes. Contreras (1994) afirma que la reflexión es un proceso que se orienta a la acción y está históricamente contextualizada; es una práctica que vincula pensamiento y acción. Afirma Schön que cuando un profesional toma conciencia de los marcos en que se desenvuelve la acción, descubre otras posibilidades de encuadrar su práctica y toma conciencia de los dilemas. El aislamiento de los profesores en las instituciones educativas y la rutinización de las prácticas son obstáculos a la reflexión desde la acción. Desde otra línea teórica y retomando el concepto de habitus desarrollado anteriormente, Edelstein (1995) plantea que un modo posible de introducir cambios en él es el trabajo reflexivo acerca de las percepciones y representaciones puestas en juego en la práctica, lo que implicaría generar una discontinuidad temporal con respecto a la situación presente. Afirma además, que esto es posible con la mediación de otros sujetos en posición de observadores.

\section{Construyendo...}

\section{... desde los cimientos metodológicos}

La metodología de nuestra investigación se enmarcó en un modelo cualitativo de corte fenomenológico, orientada a la construcción de aproximaciones teóricas de carácter interpretativo.

Por investigación cualitativa entendemos aquella que se inscribe en la aproximación a un fenómeno estudiado, a través de una explicación descriptiva del mismo a partir de las voces y experiencias de los actores en el contexto en que se producen, desde un punto de vista hermenéutico. Eisner (1998) sostiene que somos capaces de re-conocer y percibir cualidades no sólo en los objetos sino en las personas y en los hechos, entendiendo por re-conocimiento el proceso de establecer categorías y por percepción el proceso que permite conocer e interpretar. A partir de la percepción y el re-conocimiento generamos experiencias y éstas son construcciones cognitivas, al igual que aquellos. Sostiene además que mientras conocemos las cualidades, alcanzamos la experiencia y a través de ella conseguimos producir significado en un tiempo espacio determinado, que condiciona y construye el modo de percibir, atravesado también por la historia del sujeto.

Es precisamente la percepción de los actores, lo que dicen, lo que hacen, lo que escriben, lo que se constituye en pilar de la perspectiva fenomenológica; la mirada desde este enfoque está dirigida a los significados que los sujetos atribuyen al mundo. Sus acciones se producen basadas en estos significados y aquellas serán interpretadas acorde a estos. Dice Woods (1998) que el yo del investigador está puesto en juego desde el planteo del tema que por alguna razón ha despertado su interés, más allá de conjugarlo con elementos de pertinencia y relevancia para el campo al cual el fenómeno pertenece. Sostiene que por más rigurosidad que haya en los métodos 
empleados, los investigadores involucran su subjetividad en la interpretación. Eisner (1998) afirma que el carácter interpretativo de la investigación cualitativa está dado por la elección de determinados constructos teóricos y por la relación experiencial que el investigador tiene con la situación estudiada. Por su parte, Taylor y Bogdan (2000) sostienen que el investigador cualitativo suspende sus creencias, representaciones y predisposiciones, no dando nada por sobreentendido siendo éste uno de los aspectos que dará validez a su estudio. Los métodos empleados asegurarán "(...) un estrecho ajuste entre los datos y lo que la gente realmente dice y hace (21)".

Consideramos, sin embargo, que más que por una suspensión de su subjetividad, la validez de la investigación en este sentido estará dada además, por el reconocimiento de aspectos de su implicancia (con el tema, con los sujetos, etcétera) que hacen a lo transferencial y también a la deconstrucción de la misma analizándola; decimos análisis en el sentido de distinguir y separar las partes de un todo para llegar a conocer sus elementos (DRAE, 2001). Devereux (1983) nos advierte acerca de los fenómenos de transferencia y contratransferencia en la investigación, en cuanto a que ésta puede verse obstaculizada por la ansiedad que produce la superposición entre sujeto e investigador. Se hace necesario un análisis que establezca la distinción entre uno y otro para que la percepción e interpretación de los datos no esté distorsionada.

El proceso de investigación supondrá acercamiento y distanciamiento en proceso dialéctico. La objetivación de su condición de sujeto investigador lo llevará al distanciamiento de la experiencia mediado por lo conceptual que será red de sostén para conectar los datos y descubrir, de modo tal que el "El pensamiento se aproxima a lo distante, pero lo distante también se acerca al pensamiento... (Berger: 2001, 91)".

Lo expuesto anteriormente se relaciona con el carácter emergente que hace a la flexibilidad del diseño metodológico, entendiendo por tal aquel diseño que si bien se esboza al comienzo del estudio, se reformulará al tiempo que se realiza el trabajo de campo y el análisis primario de los datos a partir de ciertos criterios (Valles, 1997). La flexibilidad como característica de la investigación conduce a que la investigación cualitativa sea considerada un arte (Taylor y Bogdan, 2000), desde el momento en que es el investigador quien crea su propio método. Arte en la medida en que en el proceso creativo están presentes, entre otros, la flexibilidad, la intuición y el pensamiento cualitativo (Eisner, 1998). Arte además por la originalidad que supone el carácter irrepetible de la experiencia (Benjamin, 1989), el aquí y el ahora de la investigación. Arte también por la incertidumbre que subyace en este tipo de investigación al no operar con certezas regladas, lo que hace del proceso de investigación una heurística.

Ubicados desde estos fundamentos es que realizamos el diseño metodológico a través de herramientas específicas.

\section{...el diseño metodológico}

Nuestra investigación se inscribió en un modelo de enfoque cualitativo de corte fenomenológico orientada a la comprensión de los elementos de análisis de las prácticas de los profesores adscriptores de CV-D y de la reflexión en torno a las mismas. Nos propusimos detectar prácticas de enseñanza de profesores adscriptores en presencia de estudiantes de profesorado e indagar elementos de análisis de las prácticas de enseñanza y reflexión de los mismos para comprender la manera en que se produce la reflexión en ellos, desde la visión de los actores involucrados. La investigación se realizó durante 2007 y 2008 con seis profesores adscriptores de de CV-D, que desempeñan su tarea en centro educativos de Ciclo Básico y Bachillerato, con practicantes de los cursos de Didáctica I en el primer caso y Didáctica II en el segundo. 
Para seleccionar nuestra muestra y de acuerdo a lo expuesto con relación a los profesores novatos y experimentados, tomamos como criterios la antigüedad y la formación docente, lo cual contempla el criterio de heterogeneidad de la muestra. Con respecto al primer criterio, definimos integrar la muestra con tres profesores adscriptores cuyo desempeño en el rol fuera menor a cinco años y otros tres, mayor a diez años. Con relación al segundo criterio consideramos pertinente seleccionar a los docentes de acuerdo también a su formación profesional: egresados y no egresados del IPA. La muestra se conformó por profesores adscriptores que cumplieran con ambos criterios simultáneamente.

Seleccionamos a cinco estudiantes que realizaron su práctica con los adscriptores elegidos, manteniendo la proporcionalidad con respecto a la muestra de los docentes.

Para establecer nuestras primeras dimensiones de análisis, entrevistamos a dos informantes claves. Posteriormente, observamos clases de dos profesores adscriptores en presencia de estudiantes practicantes. Realizamos entrevistas a todos los profesores adscriptores. Entrevistamos a los estudiantes practicantes a fin de conocer sus concepciones con respecto al rol y la tarea del profesor adscriptor. Para validar nuestros hallazgos, entrevistamos a distintos referentes a saber: la Subdirectora del IPA, la Subdirectora del liceo $X$ y una profesora de Didáctica de la Historia del IPA. Fueron elegidos de acuerdo a los siguientes criterios: la primera por ser el centro de formación docente referido en nuestra investigación; la segunda por gestionar un centro educativo que recibe por año un alto número de practicantes y la tercera por contar con reconocimiento académico y no ocupar cargos de gestión en ninguno de los ámbitos referidos.

\section{...utilizando herramientas técnicas}

La recolecta de datos se realizó mediante las técnicas de observación no participante y entrevistas.

Realizamos observaciones de clase en condiciones naturales; las mismas tuvieron el carácter de no participantes puesto que habilita la comprensión de los significados que emergen de las acciones de los sujetos en el contexto real. Un elemento a tener en cuenta es el control del sesgo del observador (Valles, 1997). Las observaciones fueron de carácter abierto y se efectuaron a fin de detectar las estrategias de enseñanza desplegadas por cada adscriptor, el vínculo establecido con el estudiante practicante y elementos que dieran cuenta del análisis de sus prácticas y la reflexión, en sentido amplio, en el contexto áulico.

Trabajamos con entrevistas semi-estructuradas y estructuradas. La entrevista es una de las técnicas que mejor permite acercarnos a las significaciones de los actores desde los discursos desplegados acerca del fenómeno que buscamos comprender. Las entrevistas semi-estructuradas fueron realizadas a los informantes claves y las organizamos basadas a preguntas que permitieran aproximarnos a los tópicos relevantes del fenómeno investigado. Este instrumento nos permitió comprender los aspectos claves de lo referido a las prácticas de análisis y reflexión de los profesores adscriptores y derivamos de ambas entrevistas nuestras primeras dimensiones de análisis. Las entrevistas estructuradas las organizamos con criterios diferenciados para los profesores adscriptores, los practicantes y los referentes. En el caso de los adscriptores, la entrevista permitió aproximarnos a los modos de acercamiento a la docencia, a las concepciones de formación y desarrollo profesional: del rol y la tarea de los profesores adscriptores: del rol de la práctica docente en la formación docente: de sus prácticas como adscriptor, las referidas al practicante y a los efectos de su presencia en el profesor adscriptor, al profesor de Didáctica, a la evaluación y a la reflexión en torno al análisis de sus prácticas. Con respecto a las entrevistas 
a los estudiantes practicantes, nos aproximamos a las concepciones de los estudiantes acerca del rol de la práctica docente, del rol y la tarea del profesor adscriptor, así como a los sentidos que adquieren las "buenas experiencias" vividas con ellos. Las entrevistas estructuradas a los referentes fueron implementadas durante la última etapa de la investigación como forma de validación metodológica.

La validación de nuestro diseño metodológico la efectuamos por medio de una triangulación que consiste en la realización de un análisis interrelacionando los datos obtenidos a través de las diferentes técnicas (Taylor y Bogdan, 1996:91-32).

\section{Para habitar el territorio...}

\section{....entrevistamos a los expertos en busca de otras herramientas}

Los criterios que nos propusimos para la elección de los informantes claves fueron la experticia y el haber sido docente de alguno de los cursos de Didáctica del profesorado de CV-D. Las dos entrevistas fueron estructuradas en base a tres niveles diferentes: el primero exploró la historia de formación de los entrevistados, a fin de aproximarnos a su opción por la docencia en CV - D; el segundo, intentó indagar las prácticas docentes autónomas y el desarrollo profesional, a través de la historia laboral de los entrevistados; el tercer nivel pretendió explorar concepciones acerca de la tríada de actores participantes en la formación de un docente de CV- D, en particular lo referido al profesor adscriptor. Establecimos aquellos aspectos que convergieron notoriamente, dando cuenta también de algunos no concurrentes pero que evaluamos como importantes para su posterior indagación en las entrevistas a profesores adscriptores y practicantes.

Para poder construir las dimensiones de análisis que orientarían la confección de herramientas para la recolecta de datos, establecimos tres órdenes o grados de análisis. El análisis de primer orden fue el que consistió en la exploración de cada una de las entrevistas a los informantes claves a fin de detectar tópicos relevantes. El de segundo orden nos permitió percibir elementos convergentes entre ambas y algunos emergentes, en cada uno de los tres niveles de análisis que nos propusimos para su estudio; lo llamamos análisis intra - nivel. Un análisis de tercer orden, consistió en establecer las recurrencias de las convergencias emergidas en cada uno de los tres niveles primarios de análisis.

En el primer nivel de análisis percibimos que en distintos momentos de sus narrativas los informantes claves dieron cuenta de la reflexión en torno a la disciplina y a la didáctica disciplinar a punto de partida de diversas situaciones enmarcadas en un contexto amplio del que la formación es parte. Indagar la historia de formación de los informantes claves nos permitió aproximarnos a algunos de los motivos de su opción por la docencia en CV-D, de los que emergen diferentes modos de acercamiento a la misma. Pudimos reconocer indicios del impacto de la formación docente en las prácticas así como la noción de construcción del rol docente a través de las prácticas de enseñanza. Detectamos también concepciones acerca de la formación docente en particular de la tríada de actores participantes de la práctica docente enmarcada en el curso de Didáctica de CV - D del IPA, de los vínculos generados en ella y de las prácticas de estos actores incluyendo las instancias de evaluación. Estas concepciones permiten cierta "modelización" del rol y las prácticas de enseñanza. Percibimos también el modo en que los practicantes eligen a sus profesores adscriptores. Reconocimos concepciones de la disciplina en el marco del currículum, caracterizada como espacio subjetivante desde lo epistemológico y lo moral. Convergieron también elementos vinculados a lo memorable y otros del orden de la búsqueda, del descubrimiento y del placer. 
Percibimos que ambos entrevistados, desde una historia laboral diferente, desplegaron elementos que hacen por un lado al inicio de la práctica autónoma que se desarrolló posteriormente desde diferentes lugares, en diferentes momentos. Por otra parte, nos acercamos a las concepciones de desarrollo profesional de los entrevistados y los modos de construir conocimiento en la práctica profesional. Convergen también aspectos que vinculan la búsqueda de lo nuevo como desafío que orienta el desarrollo profesional y deriva en elementos del orden del placer.

Pudimos percibir elementos en torno al análisis y la reflexión sobre las prácticas docentes, en particular las de enseñanza de la CV -D, de las que se derivan la preocupación por la buena enseñanza y las concepciones de la asignatura; observamos también concepciones acerca del rol docente. En esta línea emergen las manejadas sobre evaluación, fundamentalmente a partir de la entrevista a la informante clave. A través del análisis fuimos identificando componentes de lo memorable, dado a través de situaciones que generaron algún cambio en las teorías y prácticas de los entrevistados.

El tercer nivel de análisis exploró las concepciones emergentes acerca de la tríada de actores participantes en la formación de un docente de CV-D, en particular lo referido al profesor adscriptor. El análisis de las entrevistas nos permitió evidenciar la concepción de desarrollo profesional de los informantes claves, a partir de su condición de profesores de Didáctica de la CV - D en el IPA. Convergen las concepciones acerca del momento de la historia personal y profesional en que se asume el rol de profesor adscriptor.

De la exploración de los datos obtenidos en las entrevistas encontramos concurrencias entre las concepciones acerca de la importancia de la práctica docente en la formación de un estudiante de profesorado de CV - D, percibida como espacio de búsqueda y construcción del rol docente por parte del practicante, lo que supone múltiples responsabilidades para el profesor adscriptor. Convergen en concebirlo como espacio complejo, a partir de la consideración de elementos contextuales y del "juego de miradas" entre los actores intervinientes en el proceso de formación de un docente. Coinciden en concebirlo como espacio de construcción de subjetividad. Ambos concuerdan en señalar que la práctica docente posibilita la co - autoría de las prácticas de enseñanza; en la noción de co - autoría subyace la de creación. Coinciden las concepciones acerca del practicante.

Del análisis de ambas entrevistas surgieron en concordancia las concepciones acerca de las características del profesor adscriptor y de sus prácticas de enseñanza, en el proceso que implica desde el practicante, aprender a enseñar. Emergen concepciones acerca de aspectos referidos al profesor adscriptor como modelizador de las prácticas. Concuerdan también que la tarea de profesor adscriptor que supone la presencia de un estudiante practicante en el aula, favorece la reflexión y el análisis acerca de las propias prácticas y en que impacta en las mismas; conciben la tarea como parte del desarrollo profesional.

Pudimos percibir a través del análisis, la convergencia de las concepciones acerca del vínculo entre el profesor de Didáctica y el profesor adscriptor considerando que comparten la formación del practicante; desde ahí emerge la evaluación. Vimos también el modo en que la figura del profesor de Didáctica opera a nivel fantasmático en el profesor adscriptor en las instancias de las visitas de evaluación.

Otra convergencia se establece en la necesidad de la formación del profesor adscriptor para el desempeño de su rol. 
Del análisis resulta que los practicantes memorables aparecen vinculados a prácticas de buena enseñanza; subyacen en ellas elementos referidos a lo nuevo y a lo diferente que afectaron de algún modo al profesor adscriptor o de Didáctica.

Las diferentes concepciones emergentes están atravesadas por los componentes epistemológico y ético de la buena enseñanza.

...para construir espacios que permitieran interpretar

Establecidas las convergencias intra-nivel a partir del análisis de las entrevistas, procedimos a establecer las recurrencias inter - niveles.

Derivado de este análisis de segundo orden, pudimos percibir que los elementos que convergieron fueron los relativos a la formación y el desarrollo profesional docente. Por otro lado, surgen recurrencias en torno a las concepciones acerca del rol docente y del rol del profesor adscriptor en particular y las referidas a las prácticas de enseñanza, a la asignatura y a la evaluación. Por otra parte, coincidieron las relativas a los vínculos y las prácticas del profesor adscriptor, el practicante y el profesor de Didáctica. Concordaron también elementos relativos a lo memorable. Establecidas estas coincidencias, creamos tres grupos de dimensiones de análisis, en cada uno de los cuales incluimos sub - dimensiones. El primero lo construimos en torno a las concepciones; el segundo con lo emergente acerca de la formación y al desarrollo profesional y el tercero, con lo relativo a lo memorable. El primer grupo de dimensiones indagaría la formación y el desarrollo profesional considerando la formación docente de grado, otros ámbitos de formación, la historia profesional y el curso para profesores adscriptores. Dentro de la dimensión concepciones, establecimos explorar las relativas a la enseñanza en general; a la asignatura; al rol del profesor adscriptor y sus prácticas; al practicante; al vínculo con el profesor de Didáctica y a la evaluación. El último grupo de dimensiones exploraría lo referido a lo memorable en el que separamos de modo artificial, lo relativo a la historia personal; también integramos como sub - dimensiones, los docentes memorables y los practicantes memorables.

\section{...Descubriendo el territorio...}

\section{...para aproximarnos a las formas de habitar}

Partimos de la noción de habitar entendida como un modo propio de estar en el mundo que hace a los modos de ser, estar, pensar, representar en un espacio - tiempo determinado. El habitar supone un espacio en el que algo tiene o puede tener lugar. Es a través del habitar que el espacio se puebla y se significa transformándose.

Analizada toda la información surgida de las entrevistas y las observaciones de clase, percibimos que los profesores adscriptores construyen su rol y diseñan su tarea a partir de la situación de encuentro con cada practicante. El profesor adscriptor tendría el carácter de "docente - bisagra" como articulador de dos ámbitos de formación; es una figura "entre" el docente de secundaria y el de formación docente. Se deriva entonces que no hay modo único de construirse en el rol de adscriptor y de llevar a cabo su tarea. Rol y tarea son indisociables y uno necesariamente implica al otro, pero las características convergentes nos permiten considerar por un lado, modos de habitar el rol y por otro, modos de habitar la tarea. Estos modos de habitar el rol y la tarea de los profesores adscriptores, tienen en común elementos que emergen de lo memorable y otros que derivan de considerar las características de un buen profesor adscriptor que en el desarrollo de nuestro trabajo llamamos "modelo". 
Los modos de habitar el rol están caracterizados por elementos que surgen de la historia personal y profesional, de las concepciones del rol de profesor adscriptor de CV - D, de los vínculos que establecen con los practicantes y los profesores de Didáctica y elementos que remiten a concepciones acerca de los practicantes, que emergen de lo memorable. Los modos de habitar la tarea se conforman a partir de las concepciones acerca de la formación, la práctica docente y la evaluación y componentes de lo memorable.

\section{Los modos de habitar el rol}

La historia personal y profesional de los adscriptores se entrecruza con los modos de acercamiento al ejercicio de la docencia en forma autónoma. En este sentido encontramos dos formas de acercamiento: una que establece el inicio de la práctica docente autónoma en el momento de egresar del IPA y otra, en la que factores de orden personal llevaron al ejercicio de la profesión sin tener formación docente de grado. Entre estos encontramos razones que obedecen a lo dispuesto en la normativa, no se requiere el título habilitante para ejercer la docencia. Los factores que orientaron la opción por la docencia se relacionan con un "gusto" particular por la disciplina. No encontramos convergencias con el planteo de una profesora adscriptora no egresada del IPA, cuya opción estuvo orientada por el deseo de trabajar con adolescentes.

Aparecen elementos convergentes relacionados con momentos claves de su historia profesional en la cual se inscribe el desempeño del rol de adscriptor. El primer momento clave corresponde al inicio de la práctica autónoma, caracterizado por la incertidumbre que produce el encuentro con la complejidad de las prácticas de enseñanza, al considerarlas en sus contextos. Ante esto, los profesores generaron estrategias que permitieran disminuir el desconcierto inicial, apoyándose en colegas experimentados o creando equipos que permitieran sostenerse en otros para poder pensar, lo cual coincide con las caracterizaciones de los profesores novatos que consideramos a nivel teórico. Con el tiempo surge la necesidad de consolidarse en su opción y en su modo de ser docente, apostando a su desarrollo profesional. Así, encontramos que algunos entrevistados ampliaron sus ámbitos de formación y actuación profesional. Otro momento clave es el del inicio en el desempeño del rol de profesor adscriptor; aparece definido por la incertidumbre que el nuevo rol plantea, en un momento del desarrollo profesional docente en que como profesor de educación media se sentía consolidado; vale decir, cuando lograba la pericia en su rol, se plantea el momento de iniciación en el otro. La incertidumbre se ve acrecentada por la presencia de otra mirada en el aula, que observará sus prácticas y a quien necesariamente tendrá que observar. Sin embargo, la presencia del practicante, es caracterizada como "oxigenante" para las propias prácticas.

El desafío ante lo nuevo es asumido con placer por el descubrimiento de desarrollar el rol docente desde otro lugar, un lugar nuevo que supone cierto grado de expansión en el desarrollo profesional. "Fructificar", "oxigenar", "aire nuevo", todos elementos metafóricos que significan la presencia del practicante como oportunidad para la revisión de la propia práctica, produciéndose con el tiempo, la flexibilización del ser y hacer del profesor adscriptor a la vez que va emergiendo una "libertad responsable". Surge la importancia del practicante en el proceso de construcción del rol. Presencia y expansión.

El modo en que los practicantes eligen a sus profesores adscriptores asume dos modalidades emergentes; una, vinculada con la afinidad con el profesor adscriptor por la existencia de un conocimiento previo, y otra relacionada con la conveniencia horaria y la cercanía del liceo de práctica a su domicilio o a su trabajo. Se establecieron recurrencias entre los modos diferenciados de elegir al profesor adscriptor, según se trate del curso de Didáctica I ó II; en el primer caso, 
optaron de acuerdo con la primera modalidad citada y en el segundo, intervienen factores que hacen predominar el conocimiento previo del profesor adscriptor. Los motivos que orientan este modo de elección remiten al estilo docente del adscriptor lo cual dota a esta modalidad de un componente ético, epistemológico y didáctico.

Percibimos recurrencias en la concepción del rol de profesor adscriptor como co - visor y acompañante; es el que apoya a sus practicantes en su proceso y los critica constructivamente porque sabe comunicar. La capacidad de comunicarse implica también la comprensión y la adaptación al contexto de comunicación, lo cual parecería ser un componente del "oficio docente". En este sentido, es el que brinda los secretos de oficio derivados de la experiencia, que transmite generosamente a sus practicantes, asegurando de este modo su continuidad, lo que hablaría de alguien que desde el "decir" del presente se expande al futuro a través de lo que aprendió a lo largo de su historia. Presencia y expansión.

Emerge una concepción del rol que remite a la actitud docente de "generar el enigma" para propiciar la emergencia del deseo que impulsa a buscar un modo propio de asumir las prácticas de enseñanza de la asignatura. El buen profesor adscriptor estimula y sostiene los procesos de investigación, al concebir la práctica docente como un espacio de exploración. Puede generar el enigma y promover procesos de investigación, porque el buen profesor adscriptor es reflexivo e inquieto y además es capaz de aprender junto al practicante, está al lado, desde un modo de ser. La inquietud por conocer se sustenta en una doble dimensión, ética y epistemológica. El profesor adscriptor "sabe" y "quiere" lo que hace. Esto remite a lo epistemológico de la docencia de la CVD y al saber - hacer del oficio. El querer lo que hace entraña la dimensión ética del ser docente: el amor a la docencia a través de la disciplina es también el amor al Otro que la tarea de la enseñanza supone.

En cuanto a las características del buen profesor - adscriptor convergen elementos referidos al profesor adscriptor que habilita al practicante a la búsqueda de una modalidad propia y que guía respetando la individualidad de cada estudiante. Sería aquel que es autor - creador y desde ese lugar promueve procesos de autoría en el practicante. Este profesor adscriptor habilitaría al practicante a habitar la práctica docente desde su modo de ser; habilita y sostiene, sería "lo bastante bueno" para estar cerca desde cierta distancia, andamia y desandamia. Este profesor adscriptor es paciente, por lo tanto espera que el Otro vaya emergiendo desde su ser y su hacer; lo hace desde la firmeza que contiene pero firmeza no es rigidez. Desde la flexibilidad, tendría la capacidad de hacer lugar a la participación del practicante apoyándolo. A través del vínculo que generan profesor adscriptor y practicante, se reconoce la alteridad del Otro en construcción. En un sentido profundo implica el reconocimiento del Otro, de su libertad, de su capacidad de decidir con intencionalidad. Así el practicante es reconocido como alteridad que puede afectar y que con su presencia posibilita modos de hacer a través de una mirada nueva. El buen profesor adscriptor es aquel que no tiene deseos de "dejar huella" porque desea que cada practicante vaya encontrando - se a través de la pregunta fundante acerca de qué es ser docente. Estos buenos profesores adscriptores que podrían pensarse como las representaciones y concepciones de los practicantes con las que los estudiantes se acercan al espacio de práctica docente, tienen características comunes con los profesores adscriptores que encontramos en las narrativas de los practicantes investigados y en los discursos de los que entrevistamos, sobre todo en aquellos casos en que el modo de elección estuvo orientado por el conocimiento previo.

Los modos de habitar el rol se fundan en la doble dimensión ética y epistemológica. 


\section{Los modos de habitar la tarea}

El espacio de práctica docente es concebido por todos los investigados como espacio en el que concurren los saberes disciplinares, los saberes de otros espacios de la formación docente que deben conjugarse en una situación particular de enseñanza. Los saberes teóricos se significan desde la experiencia en el contexto de la práctica y en el encuentro con los estudiantes adolescentes, con la complejidad que supone el campo educativo. La práctica docente es concebida como "el lugar de bajar los conocimientos a tierra" en un aula que es "reflejo de la realidad cultural (Diego)".

La práctica docente es entendida como un espacio de exploración y búsqueda en el que el practicante "hará su camino", irá "probando lo que será su futura profesión" e irá encontrando su lugar en tanto transmisor de saberes en contextos particulares. En este sentido, no se establecieron recurrencias en la demanda explícita de que sea el profesor adscriptor el que establezca "un orden jerárquico" a fin de que el practicante sepa cuál es su lugar. El practicante sabe que el profesor adscriptor lo reconoce como un par desde la asimetría y lo habilita a trabajar a partir de sus ideas, guiando los procesos de reflexión y análisis, sin imprimir una dirección ajustada a sus expectativas.

En ese espacio el practicante puede investigar, experimentar, probar y equivocarse, pero basándose en el conocimiento disciplinar, lo cual remite a una heurística de la práctica docente; el profesor adscriptor ejerce una "vigilancia epistemológica" y orienta la búsqueda. En esta concepción, el profesor adscriptor es alguien que está lo suficientemente cercano como para sostener y lo suficientemente lejano para habilitar, para dar lugar. Es una concepción de la práctica docente que remite a lo ético, a lo epistemológico y a lo heurístico.

Para que el practicante pueda asumir el espacio de práctica como propio, habitar su práctica, es necesario que el vínculo se establezca a partir de un espacio de confianza. El profesor adscriptor aparece como Otro disponible que habilita, que da la posibilidad de preguntar, entendida como curiosidad acerca de lo ignorado o no comprendido, dimensión que está presente en el aprendizaje y emerge desde la dimensión ética del vínculo.

Se establecen recurrencias en caracterizar la evaluación como crítica constructiva y el profesor adscriptor sostiene esa instancia conteniendo también la frustración que pueda generar. La buena evaluación es aquella en que los actores logran reflexionar acerca de las prácticas de enseñanza.

Tendremos entonces que en el espacio de práctica docente, el practicante va significando los conocimientos teóricos y prácticos disciplinares desde la experiencia en el contexto de práctica. Alli encontrará la complejidad de lo contextual y se verá enfrentado a situaciones que limiten o sean percibidas como problemas, lo cual generará búsquedas. Encuentra como referente al profesor adscriptor que, de acuerdo a recurrencias, resuelve dificultades buscando soluciones alternativas que posibiliten buenas prácticas. Esto hace de la práctica del profesor adscriptor una práctica heurística a la que se agrega la dimensión ético -política de lo contextual.

Una de las características que pudimos reconocer de las prácticas de los profesores adscriptores en presencia de practicantes es que se relacionan con los practicantes y los estudiantes liceales con afecto, dando lugar a diálogos espontáneos. Es a través del afecto que señalan límites habilitantes a los estudiantes. Percibimos la misma estrategia de inicio en la que recapitularon la clase anterior y la actividad planteada, de modo de establecer nexos entre la clase anterior y la presente. Teniendo en cuenta la complejidad del tema que abordan, diseñaron actividades que favorecieran la comprensión de los contenidos a través de situaciones - problema que basándose en los conocimientos que los estudiantes ya tenían, plantea el desafío del conocimiento a aprender. 
Presentaron la actividad desde un lugar vinculado al placer. Cada actividad suponía procesos cognitivos complejos que fueron andamiados por los profesores adscriptores y sus practicantes a través del diálogo que intentaba centrar a los estudiantes en las estrategias que tendrían que poner en juego para resolver la actividad. Los profesores adscriptores desandamiaron en el momento de la clase en que se propuso otra actividad. Las actividades planteadas implicaron la resolución desde modos de pensamiento convergente y divergente, en los que la percepción, la memoria, la atención, la conservación de la forma, la reversibilidad estaban presentes así como la flexibilidad y la intuición como formas de poder abordar la ambigüedad presente en la actividad. En ambas percibimos la apelación a pensar hecha a los estudiantes.

Pudimos reconocer componentes creativos. En un caso lo percibimos a través de las acciones, palabras e intenciones de la propia docente, en su intencionalidad explícita de pensar y ver de un modo diferente, incluso la vida. En el otro, el componente creativo estuvo dado por la inclusión de un juego de simulación informático como novedad, reconociendo que no era su idea sino la de una ex - practicante. En ambos casos, la dimensión creativa tuvo un componente ético; en un caso, desde el reconocimiento de la ex - practicante como practicante memorable de la profesora adscriptora, que es evocada por haber generado algún efecto en el profesor adscriptor, en este caso, la inclusión de la nueva tecnología. A través de su actitud se evidenció que los practicantes reconstruyen, potencian y expanden. En el otro caso, la dimensión creativa estuvo presente en la estrategia utilizada por la profesora cuando los estudiantes manifestaron su conflicto cognitivo, a través de la cual desplegó diferentes estrategias de resolución heurísticas, para que los alumnos comprendieran la situación problema planteada. Su discurso reforzó la necesidad de "ver de una manera distinta", no sólo el dibujo sino también la vida, apelando al pensamiento divergente. Sostuvo el mismo discurso al dialogar con la practicante incluyendo elementos de humor y apelando al reconocimiento de la situación contextual.

Con relación al lugar que las profesoras adscriptoras dieron a los practicantes, encontramos que los incluyeron desde la participación autónoma.

Percibimos que la reflexión estuvo presente, en un caso a través de la inclusión del juego de simulación; en el otro, a través de la explicitación de sus intenciones y la provocación a un modo de pensar diferente, a través del uso de diversas analogías, lo cual supone un modo de resolución heurística ante la situación - problema.

Las cualidades que percibimos en todas las prácticas evocadas por los investigados se vinculan por un lado a prácticas de enseñanza diseñadas en co - autoría, esto es entre el profesor adscriptor y el estudiante practicante; por otro lado fueron propuestas que pusieron la asignatura al borde, al integrar en las propuestas de clase elementos perceptivos no visuales, favoreciendo otros modos de acercamiento a lo visual. Esto supone una concepción abierta de la asignatura en el que se integra la novedad; converge de esta manera con la concepción de asignatura como espacio subjetivante del currículum. Surgen recurrencias también con relación a prácticas de enseñanza diseñadas en forma autónoma por el practicante, sostenidas desde el cuestionamiento por el adscriptor. Se evocan porque los practicantes lograron defender su propuesta con convicción y fundamentos no sólo disciplinares sino contextuales. De estas prácticas memorables se destaca el componente intuitivo, ético y epistemológico. Por otra parte, en estas prácticas memorables, aparecen componentes de la "generación del enigma" y del placer, tanto en los estudiantes liceales, como en el practicante, como en el profesor adscriptor.

La contextualización de la práctica remite a lo ético. La inclusión de lo nuevo, lo diferente y lo creativo, producto de una búsqueda en acuerdo con los contenidos disciplinares caracteriza estas prácticas como heurísticas con sentido ético y epistemológico. 
Se establecen concurrencias entre las "buenas experiencias" evocadas por los profesores adscriptores y las evocadas por los practicantes; ambos tipos presentan los rasgos de la buena enseñanza en su doble dimensión.

A partir de lo desarrollado, percibimos convergencias entre algunos elementos de las "buenas experiencias" y los derivados del análisis de las clases observadas. Coinciden en haber habilitado la participación del estudiante. Por otra parte, todas las propuestas planteaban desafíos cognitivos que implicaban la puesta en juego de aspectos del pensamiento divergente y convergente. Se relacionan con prácticas en las que lo nuevo se incluye como disparador. Percibimos en todas la intencionalidad docente de favorecer la construcción del conocimiento y alcanzar una comprensión genuina. Se establecen concurrencias en la concepción de la práctica docente del estudiante de CV-D en sus dimensiones heurísticas, éticas y epistemológicas. Tienen además las características de la clase reflexiva.

Otros elementos recurren en la necesidad de un buen vínculo entre el profesor adscriptor y el profesor de Didáctica, atendiendo de esta forma a la tarea que los reúne: la formación del estudiante practicante; el buen vínculo facilita el aprendizaje. Estos vínculos caracterizados como buenos, se basan en el respeto mutuo y posibilitan el crecimiento de los profesores adscriptores. Las "buenas experiencias" de evaluación con el profesor de Didáctica evocadas por los profesores adscriptores se vinculan a profesores que habilita al practicante para generar propuestas no convencionales, abiertas, o se involucra en las actividades propuestas por el practicante. Emerge la flexibilidad como característica del profesor de Didáctica, atendiendo a elementos contextuales en situación de evaluación.

Percibimos recurrencias en cuanto a la necesidad de formación para el desempeño del rol ya que no basta con la experiencia, siendo necesario saber cómo estructurar la situación de aprendizaje del estudiante de práctica docente. Esta profesionalización redundaría en beneficio del practicante. Con menor grado de convergencia surge la importancia del curso para adscriptores.

\section{Las prácticas heurísticas con sentido epistemológico y con sentido ético}

Podemos decir, a partir del análisis de la información obtenida, que tanto el profesor adscriptor como el practicante se constituyen y construyen en la situación particular de la práctica docente a través de un proceso de construcción afirmativa.

La práctica docente es concebida como espacio fundamental de la formación docente ya que es allí donde confluyen todos los saberes disciplinares que el practicante tendrá que articular para lograr la transposición didáctica en un contexto determinado. Esta instancia fue caracterizada como espacio privilegiado de búsqueda para descubrir qué es ser docente de CV - D. Descubrir significa entre otros, dejar al descubierto, clarificar, moverse hacia, marchar, vagar, fluir, abrir los ojos. En este proceso de descubrimiento no hay reglas, por lo cual cada uno diseñará su modo de transitarlo, apelando a las representaciones construidas desde su biografía escolar.

El profesor adscriptor se construirá también desde sus representaciones de su formación de grado, evocará su propia experiencia de haber sido practicante, sobre todo cuando es novato en el desempeño del rol. Construye su lugar a través de búsquedas intuitivas orientadas a observar y potenciar el proceso de aprendizaje del practicante. En este proceso de construcción no hay reglas fijas. 
Se establecen puntos de contacto en la construcción de ambos roles, el de profesor adscriptor y el de estudiante practicante, sin embargo sus roles y tareas son diferentes. En el espacio de práctica docente se instituye entonces, un juego de múltiples miradas espejadas que lo complejizan. El profesor adscriptor centra su mirada en el practicante e intenta comprender cómo "ve" el otro para ayudarlo en su búsqueda; el practicante centra su mirada en el adscriptor y desde las representaciones, le devuelve una imagen especular. Ambos a su vez, miran a los estudiantes liceales que los miran. La figura que termina de complejizar el espacio de práctica es la del profesor de Didáctica. El espacio de práctica posibilita a través de la mirada, reconocer al Otro. El juego de miradas espejadas supone por el momento iniciático del practicante y el experimentado del profesor adscriptor, la temporalidad atravesando el espacio de práctica. En la posibilidad de transmitir algo al practicante futuro docente, se actualiza la propia historia de aprendizaje del profesor adscriptor que al transmitir, también se expande a futuro a través de su practicante. El practicante a su vez transmite lo nuevo y esto afecta las prácticas de su profesor adscriptor. El practicante es alguien que reconstruye y potencia al profesor adscriptor. Lo sincrónico y lo diacrónico se conjugan en un espacio que supone presencia y expansión.

El espacio de práctica supone otros espacios materiales y simbólicos, el del aula y el de los lugares interiores que en oportunidades se exteriorizan a través de la palabra que evidencia reflexión: esto es una reflexión exteriorizada. Encontramos que es a través de las búsquedas intuitivas y del modo de asumir las prácticas de enseñanza de CV-D donde se pueden percibir elementos de reflexión de los profesores adscriptores y que el proceso de acompañar a un practicante, a través de la orientación que brinda y de la pregunta que cuestiona, evidencia la reflexión en torno al análisis de sus propias prácticas.

A través del análisis de la representación de sus prácticas o de sus prácticas en situación, percibimos elementos relativos al probar, al equivocarse, al descubrir sin apartarse del rigor disciplinar; estos procesos son los que habilita en su practicante desde un sostén que supone estar lo bastante cerca para acompañar y lo bastante lejos para habilitar. Estas prácticas son de carácter heurístico y están fundadas en lo ético y en lo epistemológico. Como forma de ayudar al practicante a resolver los problemas con los que se va encontrando en el escenario de la práctica, el profesor adscriptor propicia la búsqueda de soluciones situando al practicante ante procesos de investigación en los que privilegia las estrategias de resolución heurística. La investigación heurística supone un modo de desarrollo no lineal de estrategias que permiten arribar a soluciones no siempre adecuadas. Se transforma así en un proceso creativo que no concuerda con los fines de la economía del pensamiento lógico, porque entraña la equivocación como posibilidad, la no certeza de lo encontrado.

Otro componente de estas prácticas es la concepción de la disciplina como espacio subjetivante abierto, que permite la inclusión de elementos de otras formas de representación y/o de saberes interdisciplinarios de modo tal de ofrecer a los estudiantes diferentes maneras de acceder al conocimiento, sin que por ello se diluya el carácter visual de la asignatura. Estas prácticas se asumen con el carácter de investigación, que tiene certezas del punto de partida pero no del de llegada y tienen en cuenta las características del contexto. Ampliar las puertas de entrada para que inicien el proceso de conocimiento supone componentes heurísticos, éticos y epistemológicos.

Por último, estas prácticas se fundan en el reconocimiento de la libertad del Otro que es concebido como sujeto posible, desde la responsabilidad que la tarea de acompañar el proceso de formación de un estudiante de CV-D supone. 
Diremos entonces que las prácticas de los profesores adscriptores de CV-D son prácticas heurísticas fundadas en lo ético y en lo epistemológico; al fundarse, instituirse en estas dimensiones, se significan, adquieren el sentido de lo fundante. Son entonces, prácticas heurísticas con sentido epistemológico y prácticas heurísticas con sentido ético, quedando concebidas de esta forma, según se privilegie en la intencionalidad que las impulsa, una u otra dimensión.

Las prácticas heurísticas con sentido epistemológico serán aquellas prácticas del profesor adscriptor que promueve los procesos de investigación del practicante, manteniendo la vigilancia epistemológica sobre su proceso, reconociéndolo como Otro aún en la discrepancia. Las prácticas heurísticas con sentido ético serán aquellas prácticas a través de las cuales el profesor adscriptor, desde la libertad y lo desconocido, desea que el practicante que también se desconoce, vaya buscando - se a través de la experiencia de qué es ser docente de $C V$ - $D$, renunciando así a su deseo de ser modelo para el Otro.

Dijimos que habitar era un modo propio de residir en la realidad, de manera tal que a su vez nos va diseñando y construyendo en subjetividad. Sostuvimos el habitar como construcción continua que deviene en un interjuego de acciones en espacios - tiempos que se reconstruyen, se presentifican y se expanden. La emergencia de la ética acontece cuando alguien asume la presencia del Otro como alteridad, como diferencia radical, aun a riesgo de la incertidumbre que genera, aun cuando su accionar sea contrapuesto al propio. El profesor adscriptor habilita el accionar vigilando epistemológicamente desde la ética. Buena enseñanza. La ética es un modo de habitar. Finalmente proponemos, una didáctica habitada, en la que se pueda "mirar a otros lugares desde otros lugares (Edelstein, 1995:106)" y habitar espacios habitables.

\section{Bibliografía}

Arieti, S. 1993. La creatividad. La síntesis mágica. México: Fondo de Cultura Económica.

Atkinson, T.; et. al. 2002. El profesor intuitivo. Barcelona: Octaedro.

Beillerot, J. 1998. La formación de formadores (entre la teoría y la práctica). Buenos Aires: Coed. Novedades educativas - UBA.

BIDDLE, B.; et. al. 2000. La enseñanza y los profesores. Tomo 1. La profesión de enseñar. Barcelona: Paidós.

Berger, J. 2001. Mirar. Barcelona: Gustavo Pili.

Benjamin, W. 1989. La obra de arte en la época de su reproductibilidad técnica. En: Discursos Interrumpidos I. Buenos Aires: Taurus.

Bourdieu, P. 1991. El sentido práctico. Madrid: Taurus.

Bransford J.; VYE, N. Una perspectiva sobre la investigación cognitiva y sus implicancias para la enseñanza. En: RESNICK, L.; KLOPFER, L. 1996. Currículum y cognición. Buenos Aires: Aique. pp. 275 - 319.

Bruner Jerome 1989. Acción, pensamiento y lenguaje. Madrid, Alianza.

Camilloni, A. et al. 1996. Corrientes didácticas contemporáneas. Buenos Aires: Ed. Paidós.

Csikszentmihalyi, M. 1998. Creatividad. El fluir y la psicología del descubrimiento y la invención. Barcelona: Paidós.

Contreras, J. 1994. Enseñanza, currículum y profesorado. Madrid: Ediciones Akal.

Davini, M. 1995. La formación docente en cuestión: política y pedagogía. Buenos Aires: Ed. Paidós. 
Devereux, G. 1983. De la ansiedad al método en las ciencias del comportamiento, 2a. ed. México: Siglo XXI.

Días, $M^{a} A$. Bocetos de un perfil docente. Los aportes de los primeros años de experiencia en el desarrollo profesional de un profesor de Dibujo - Comunicación Visual. [TESIS]. (Maestría en Educación). Montevideo. Uruguay. Universidad ORT Uruguay, Instituto de Educación, 2006. 156p.

DICCIONARIO REALACADEMIA ESPAÑOLA. 2001. 21a. ed. Madrid: Espasa - Calpe.

Díaz, G. Mentorazgo: una estrategia de desarrollo profesional. En: Educar 4 (9). pp. 24 29, 2001.

Edelstein, G.; CORIA, A.1995. Imágenes e imaginación. Iniciación a la docencia. Buenos Aires: Kapelusz.

Eisner, E. 1998. El ojo ilustrado. Indagación cualitativa y mejora de la práctica educativa. Barcelona: Paidós.

FenstermacheR, G. Tres aspectos de la filosofía de la investigación sobre la enseñanza. En: WITTROCK, M. 1989. La investigación de la enseñanza. Tomo I. Enfoques, teorías y métodos. Madrid: Paidós. pp. 150 -176.

Gardner, H. 1995. Mentes creativas. Buenos Aires: Paidós.

Grompone, A. 1952. Formación de profesores de Enseñanza Secundaria. Montevideo: Instituto de Profesores "Artigas".

Heidgger, M. 1994. Construir, habitar, pensar. Conferencias y artículos. Barcelona: Serbal. Ignacio Lewkowicz entrevistado por Luis Gruss. En: Campo Grupal 56 - mayo de 2004.

Imbernón, F. 1994. La formación y el desarrollo profesional del profesorado. Hacia una nueva cultura profesional. Barcelona: Graó.

Laplanche, J.; PONTALIS, J.B. 1974. 2ª ed. Diccionario de Psicoanálisis. Barcelona: Labor.

Litwin, E. 1997. Las configuraciones didácticas. Una nueva agenda para la enseñanza superior. Buenos Aires: Paidós.

Meirieu, P. 1997 Aprender sí. Pero ¿cómo? 2a ed. Barcelona: Octaedro.

Ricobaldi, M. Concepciones de la enseñanza. Un estudio en torno a docentes experimentados sin formación pedagógica. [TESIS]. (Maestría en Educación). Montevideo. Uruguay. Universidad ORT Uruguay, Instituto de Educación, 2004. 186p.

Romero, E. 1979. Tratado de dibujo técnico. Montevideo: Edición del Instituto Uruguayo de Estudios Preuniversitarios.

Ropo, E. Diferencias en la enseñanza de inglés: expertos y principiantes. En: CARRETERO M. 1998. Procesos de enseñanza y aprendizaje. Buenos Aires: Aique. pp. 101 - 103.

Schon, D. 1998. El profesional reflexivo. Cómo piensan los profesionales cuando actúan. Barcelona: Paidós.

SOUTO, M.; et. al. 1999. Grupos y dispositivos de formación. Buenos Aires: Editorial Novedades Educativas - UBA.

Taylor, S. J.; Bogdan, R. 1996. Introducción a los métodos cualitativos de investigación. Buenos Aires: Paidós. 
Vaillant, D. 2002. Formación de formadores. Estado de la práctica. PREAL. № 25. [online] [citado 3 enero 2007]. Disponible en Internet:

$<$ http://www.preal.org/busqueda.asp>

Valles, M. S. 1997. Técnicas cualitativas de investigación social. Reflexión metodológica y práctica profesional. Madrid: Sintas.

Woods, P. 1998. Investigar el arte de la enseñanza. El uso de la etnografía en la educación. Barcelona: Paidós.

\section{Notas}

${ }^{1}$ La asignatura adquiere diferentes nombres según los cursos en Educación Secundaria. En Ciclo Básico, es llamada Educación visual, plástica y dibujo. En $1^{\circ}$ de Bachillerato, Dibujo. En $2^{\circ}$ de Arte, Expresión plástica; $2^{\circ}$ Biológico y Científico, Comunicación visual; $3^{\circ}$ Arte y expresión, Arte y Comunicación visual II y en $3^{\circ}$ opción Matemática y Diseño, Comunicación visual y Diseño.

${ }^{2}$ El término traza tiene diversas acepciones: 1 . Huella, vestigio o rastro de una cosa o persona. 2. Habilidad que tiene una persona para hacer determinada cosa. 3. Trazado o planta de una obra arquitectónica o de ingeniería y 4 . Plan para realizar un fin. (DRAE, 2001)

En la geometría descriptiva, las trazas son la intersección de una recta, un plano o un volumen con los diferentes planos de proyección. A partir de las trazas y una proyección de la entidad geométrica, puede determinarse la otra; conocidas las trazas pueden determinarse las proyecciones o viceversa. (Romero, 1979).

*El Artículo se enmarca en la tesis de maestría de la autora, dirigida por la Mag. Mirtha Ricobaldi. Año 2008.

**Master en Educación, Universidad ORT Uruguay. Diploma en Educación, Universidad ORT Uruguay. Licenciada en Psicología, Universidad de la República. Profesora de Educación Media - Especialidad Comunicación visual- Dibujo, Instituto de Profesores Artigas. Docente de Didáctica y Heurística.Análisis del proceso creativo, Instituto de Profesores Artigas. 